\title{
Improvement of Horticultural Crops for Abiotic Stress Tolerance: An Introduction
}

\author{
Beiquan Mou ${ }^{1,2}$ \\ USDA, Agricultural Research Service, Crop Improvement and Protection Unit, 1636 East Alisal Street, \\ Salinas, CA 93905
}

Improvement of horticultural crops has traditionally focused on enhancing a plant's ability to resist diseases or insects. That is evidenced by the large number of disease- or insect-resistant cultivars or germplasm released and used. Research on crop resistance or tolerance to abiotic stresses (heat, cold, drought, flood, salt, $\mathrm{pH}$, etc.) has not received much attention. However, that is changing as a result of the research and publicity of global warming. "Adaptive research" aiming at adapting the horticultural industry to climate changes is becoming popular and is now one of the emphasis areas of funding agencies. Vegetable Breeding and Stress Physiology working groups of the American Society for Horticultural Sciences cosponsored a colloquium, "Improvement of Horticultural Crops for Abiotic Stress Tolerance," at the society's 2010 annual conference in Palm Desert, CA. With its summer heat and dry weather, Palm Desert was a perfect place to discuss the topic. Papers on pages 1068-1097 of this issue are based on presentations at the colloquium.

Although there are still different opinions and modeling results regarding how much the planet will warm up, global warming is widely accepted as fact. The warmer climate threatens the production of many horticultural crops, especially those cool-season species. Growing crops above their optimal temperature range may lead to cellular damages and the development of physiological disorders. Even warm-season crops may be affected by heat stresses during critical periods. Forecasts show that warming over the next several decades will take place irrespective of what actions we take today. Therefore, adapting horticultural crops to the changing environments may be the single most important step for us to take to mitigate the adverse effects of climate change. Plant breeding is a long-term process, often taking more than 10 years to develop a new variety, especially for tree crops. Therefore, there is an urgent need to

Received for publication 22 Feb. 2011. Accepted for publication 12 Apr. 2011.

USDA is an equal opportunity provider and employer.

This paper was part of the colloquium "Improvement of Horticultural Crops for Abiotic Stress Tolerance" held 5 Aug. 2010 at the ASHS Conference, Palm Desert, CA, sponsored by the Vegetable Breeding (VGBR) Working Group, and co-sponsored by the Environmental Stress Physiology (STRS) Working Group.

${ }^{1}$ Research Geneticist.

${ }^{2}$ To whom reprint requests should be addressed; e-mail beiquan.mou@ars.usda.gov. mitigate these abiotic stresses through development of new heat-tolerant vegetable, fruit, nut, nursery, and ornamental crop varieties that will thrive in future conditions.

Climate change may affect agriculture more through water availability than temperature. Scientists predict that the altered hydrologic cycles will change the pattern of precipitation and cause wet areas becoming wetter while dry areas become drier. Global warming may cause reduced precipitation, less snow pack, and earlier snow melt, leading to drought conditions. As global temperatures rise, we are experiencing fewer but heavier rains, which may cause a host of problems such as flooding, soil erosion, leaching chemicals from fields, compaction and low oxygen levels in the soil, and delayed planting. Warmer weather will also accelerate water transpiration from plants and evaporation from soil. According to Dr. Elwynn Taylor, professor of agricultural meteorology at Iowa State University, for every $10^{\circ}$ increase in temperature, the water requirement by a crop would increase by $50 \%$ (Anonymous, 2010). Water is a precious resource. Residential and industrial uses as well as conservation for fish and other wildlife compete with agriculture for the limited water supply. Horticultural crops typically use a lot more water than agronomic crops like wheat, corn, soybean, alfalfa, and cotton. Drought-tolerant cultivars are needed to improve water use efficiency, enhance water conservation, reduce irrigation costs, and maintain or increase the acreage of horticultural crops. For certain areas or specific seasons that are prone to flooding, new varieties should be developed to adapt to the wet soil.

Global warming is not uniform and may lead to some weather extremes. Although the general trend of temperatures is going up, we are seeing some regions or certain seasons with very cold weather, even breaking lowtemperature records. Warmer springs might make crop seedlings emerge faster, but they could be vulnerable to damage from late spring frosts or freezes. So cold tolerance is still an important trait for many crops. We need coldtolerant cultivars to extend growing areas or seasons, especially in inland areas with limited frost-free days.

In addition, $\approx 20 \%$ of the world's irrigated lands are affected by salinity (Zhu, 2001), a situation worsened by climate changes. Global warming increases the rates of evapotranspiration and crop requirement of irrigation water, which may bring more salt into the soil in arid and semiarid regions. High salinity limits crop production in $30 \%$ of the irrigated land in the United States (Kumar et al., 2004). Additionally, sea water intrusion is now affecting farmlands in many coast areas of the United States. The migration of salt water into groundwater is being exacerbated by increasing freshwater demands that are depleting coastal aquifers and the projected sea level rise caused by global warming. Acreage impacted by salinity problems is expected to increase. Growers in these regions require cultivars that can resist salt stress to sustain crop production.

Growers often face multiple abiotic stresses. For example, heat and drought conditions often come together. Abiotic stresses frequently are intertwined with biotic stresses. High temperatures and elevated $\mathrm{CO}_{2}$ levels may favor weed growth in competition with crops, making weed control a challenge for growers. Heavy rainfall may increase root diseases. Climate change may promote infestation/epidemics of plant pests/diseases because higher winter minimum temperatures enable insects, pathogens, or disease vectors to overwinter more effectively. We should breed cultivars with multiple resistances or tolerances against abiotic and biotic stresses, including herbicidetolerant traits to simplify and improve weed management.

Carbon dioxide in the atmosphere has risen $\approx 40 \%$ from 278 parts per million (ppm) before the Industrial Revolution to $389 \mathrm{ppm}$ today (Begley, 2010; Bloom, 2009). As countries continue to negotiate treaties on reducing carbon productions, atmospheric $\mathrm{CO}_{2}$ levels keep climbing, up $\approx 20 \%$ over the past half century (Anonymous, 2008). Consequently, global warming has accelerated in the past 50 years, and 2001-2010 was the warmest decade on record [World Meteorological Organization (WMO), 2011). Temperatures over the decade averaged $0.46^{\circ} \mathrm{C}$ above the $1961-1990$ mean, $0.21{ }^{\circ} \mathrm{C}$ warmer than the previous record decade, 1991-2000, which in turn was warmer than previous decades, consistent with a longterm warming trend (WMO, 2011). Temperature and $\mathrm{CO}_{2}$ concentration in the atmosphere are increasing at such a high pace, much faster than plants could evolve to adapt to the climate change. "Artificial evolution" is necessary to speed up the process and help crops adapt, sustain, and thrive in the environments of the present and future.

Adapting horticulture to future conditions is essential to meet the need of the growing population and increasing demand for fruits, vegetables, and other horticultural products. This enormous and difficult task requires tremendous research efforts from multiple disciplines. Stress physiology studies identify mechanisms of stress tolerance and provide an approach, method, and traits for screening stress-resistant genotypes. Molecular biology 
and genomic investigations lead to a better understanding of the structural organization and functional properties of genetic variation for stress-related traits, allow gene-based selection through identification of molecular markers and high-throughput genotyping techniques, and increase the gene pool available, including new sources of stress-tolerant traits or transgenes. Plant breeders translate these findings into stress-tolerant crop varieties by using all tools available that include germplasm screening, marker-assisted selection, plant transformation, and conventional breeding methods. In this issue, leading scientists in the field discuss the need, significance, and benefit of stress tolerance in fruits, vegetables, and ornamental crops; assess the current status and challenges of research in stress physiology, molecular biology, genomics, plant transformation, germplasm enhancement, and crop breeding for resistance to abiotic stresses; and identify opportunities, strategies, and priorities for further research and development.

Our ability to breed new varieties for adaptation to future environments is undermined by the systematic erosion of the biological basis of horticulture - the genetic diversity of plants, which is in turn threatened by climate changes. Present-day horticultural crops are facing a narrowing genetic base as monoculture dominates throughout the world, especially in the West. Global warming accelerates the loss of diversity because organisms may not be able to adapt to environmental changes and extinguish. Plant diversity is the key for the future horticulture industry to buffer attacks from diseases, insects, and environ- mental adversities. A diverse germplasm collection is the backbone or bloodline of any crop improvement program. Germplasm may have genes or traits we need, or they can be recombined to generate novel or enhanced traits in the battle against abiotic/biotic stresses. We should devote necessary effort and funding to safeguard, preserve, manage, collect, maintain, characterize, and use plant germplasm resources for us and our children. Indeed, climate change probably would affect future generations more than our generation.

Transgenic plants have shown great promise in tolerance to abiotic stresses such as heat, cold, drought, and salt. Despite demonstrated benefits, the commercialization of transgenic fruits, vegetables, nuts, and ornamentals has largely lagged behind the agronomic crops, although considerable research is still being conducted on these horticultural crops. Use of transgenic horticultural crops is hindered by many hurdles, including consumer acceptance, technical difficulties with the transformation and expression of transgenes in certain crops, intellectual property right, market and economic issues, and regulatory problems. Still, it is critical to continue working on these challenges to provide growers and consumers options and alternatives in solving abiotic stress problems. Because most horticultural products are for direct human consumption, it is particularly important to perform sciencebased research to assess the impact of genetic engineering on biodiversity, environmental safety, and human health.

The changing environments pose serious and imminent threats to global agriculture and place unprecedented pressures on the sustainability of horticulture industry. On one hand, the climate change makes crop production more difficult. On the other hand, population growth and health-conscious consumers demand more and better horticultural products. The challenges and opportunities coexist for our dynamic and resilient industry. In addition to curbing carbon emission and conserving resources, we should mitigate abiotic stresses and adapt to the warming planet. Hopefully, the articles in this issue will inspire more interest, discussion, and collaboration on these issues and promote future progress in this important field.

\section{Literature Cited}

Anonymous. 2008. Greenhouse gas levels waft higher. Pioneer Growing Point Magazine May: 13.

Anonymous. 2010. How real is global warming? Pioneer Growing Point Magazine January: 12-13.

Begley, S. 2010. A climate whodunit. Science nails the blame game. Newsweek December 6:23.

Bloom, A.J. 2009. As carbon dioxide rises, food quality will decline without careful nitrogen management. Calif. Agr. 63:67-72.

Kumar, S., A. Dhingra, and H. Daniell. 2004 Plastid-expressed betaine aldehyde dehydrogenase gene in carrot cultured cells, roots, and leaves confers enhanced salt tolerance. Plant Physiol. 136:2843-2854.

World Meteorological Organization. 2011. WMO statement on the status of the global climate in 2010. WMO Publication No. 1074

Zhu, J.K. 2001. Plant salt tolerance. Trends Plant Sci. 6:66-71. 